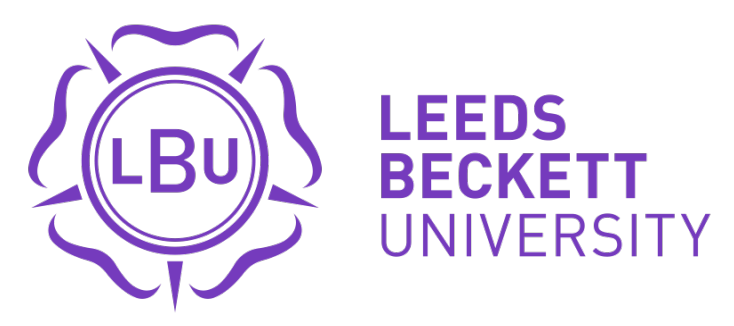

Citation:

Glazzard, J (2016) To what extent do frameworks of reading development and the phonics screening check support the assessment of reading development in England? English in Education, 51 (2). pp. 130-142. ISSN 1754-8845 DOI: https://doi.org/10.1111/eie.12119

Link to Leeds Beckett Repository record:

https://eprints.leedsbeckett.ac.uk/id/eprint/3996/

Document Version:

Article (Accepted Version)

The aim of the Leeds Beckett Repository is to provide open access to our research, as required by funder policies and permitted by publishers and copyright law.

The Leeds Beckett repository holds a wide range of publications, each of which has been checked for copyright and the relevant embargo period has been applied by the Research Services team.

We operate on a standard take-down policy. If you are the author or publisher of an output and you would like it removed from the repository, please contact us and we will investigate on a case-by-case basis.

Each thesis in the repository has been cleared where necessary by the author for third party copyright. If you would like a thesis to be removed from the repository or believe there is an issue with copyright, please contact us on openaccess@leedsbeckett.ac.uk and we will investigate on a case-by-case basis. 


\author{
Manuscript ID EIE-16-SIA-015 \\ Jonathan Glazzard \\ Institute of Childhood and Education \\ Leeds Trinity University \\ Horsforth \\ Leeds \\ LS18 5HD, UK \\ E-mail: i.glazzard@leedstrinity.ac.uk
}

To what extent do frameworks of reading development and the phonics screening check support the assessment of reading development in England?

\begin{abstract}
The purpose of this paper is to question the suitability of the phonics screening check in relation to models and theories of reading development. This paper questions the appropriateness of the check by drawing on theoretical frameworks which underpin typical reading development. I examine the Simple View of Reading developed by Gough and Tunmer and Ehri's model of reading development. The paper argues that the assessment of children's development in reading should be underpinned and informed by a developmental framework which identifies the sequential skills in reading development.
\end{abstract}

\title{
Keywords
}

Reading development, Phonics, Assessment, Primary Education 


\section{To what extent do frameworks of reading development and the phonics screening check support the assessment of reading development in England?}

\section{Introduction}

In England there has been a political emphasis on teaching children to read through a systematic approach to synthetic phonics since 2006 . This emphasis on synthetic phonics as a route into reading was advocated by the Rose Review (Rose, 2006) over a decade ago and since this time various political parties have demonstrated allegiance to this approach. Between 2006-10 the Labour government revised inspection frameworks for initial teacher training providers by placing greater emphasis on the quality of training for new teachers in this aspect of the curriculum. In 2007 the government published Letters and Sounds (DfES, 2007), a non-statutory programme to support schools with the teaching of synthetic phonics. In 2010 the coalition governed in England published the Schools White Paper, The Importance of Teaching (DfE, 2010) which emphasised that synthetic phonics was the most effective way of teaching children to read. The Teachers' Standards (DfE, 2011), which came into force from September 2012 introduced a new standard that required all teachers to demonstrate a clear understanding of systematic synthetic phonics (Teaching Standard 3). In the same year the government introduced a phonics screening check for children at the age of 6 which was designed to assess whether children had reached an age-appropriate standard in the skill of decoding. Finally, the Conservative government reiterated its commitment to synthetic phonics in the most recent White Paper Educational Excellence Everywhere (DfE, 2016). Given the emphasis on synthetic phonics this paper discusses whether theoretical frameworks of reading development and the phonics screening check are sufficient to support the assessment of reading development in England 
The synthetic phonics approach introduces beginning readers to the smallest units of sound in words. Pupils learn to read words by enunciating each of the phonemes in sequence throughout a word to read the target word. This approach is often referred to as 'blending' or 'decoding'. Beginning readers are thus able to decode print regardless of whether they understand the words they are reading. The synthetic phonics approach focuses on placing greater emphasis initially on developing the skill of decoding. Once this skill is established a greater emphasis is placed on developing the skill of linguistic comprehension.

Such an emphasis on decoding is demonstrated through the introduction of the phonics screening 'check' for all pupils in Year 1 at the age of 5-6. This is a test of decoding rather than comprehension and in order to ensure that pupils are not reading words from memory many of the words that are presented to children are pseudo 'non-words'. This means that the only way of identifying the target word is through enunciating the phonemes in sequence throughout the word and merging them together to identify the word. If children 'fail' the check in Year 1 they are required to re-take it in Year 2 (aged 6-7) in order to ascertain whether the skill of blending is secure. The necessity to re-take the phonics check raises critical questions about labelling children at an early age and the effect of failure on their self-concept. Gurney defines 'self-concept' as 'the image or picture that we have of ourselves which we carry around and use to define ourselves as well as to categorise our behaviour' (Gurney, 1988: 4). Additionally, it raises the question of whether children are actually taking a test rather than simply undertaking a check. Furthermore, the United Kingdom Literacy Association (UKLA, 2012) recommended that the 'check' should only be used to identify development needs for individual 
children rather than being used with all children on account of it holding more able readers back and potentially undermining their confidence as readers. Although blending is a prime skill through which many children learn to read (Ehri, 2005), many nevertheless learn to read through visual approaches (Ehri, 2005; Frith, 1985; Frith, 1986) and some use contextual cues as a basis for word recognition rather than relying on the skill of blending (Goodman, 1976). This might involve missing a word out, reading ahead to the end of a sentence before going back to identify the target word. Some children are fluent in reading by the time they take the 'check' (UKLA, 2012), again raising further questions about the relevance of a phonics screening check. The English language has a complex alphabetic code. There is inconsistent mapping between graphemes and phonemes, unlike in some other languages, and this raises questions about the focus on phonics and the associated skill of decoding in addressing the complex process of learning to read in English.

The purpose of this paper is to question the suitability of the phonics screening check in relation to models and theories of reading development. This paper questions the appropriateness of the check by drawing on theoretical frameworks which underpin typical reading development. I examine the Simple View of Reading developed by Gough and Tunmer (1986) and Ehri's model of reading development (Ehri, 2005). Gough and Tunmer's model has been chosen because studies have shown (for example, Hoover and Gough, 1990) that separate measures of word recognition and linguistic comprehension together give a good account of how well children comprehend what they read (Johnston and Watson, 2007). Ehri's model of reading development has been extremely influential. It encompasses the thinking of major theorists and has been tested extensively over a long period of time (Johnston and Watson, 2007). This paper argues that in view of these frameworks the phonics 
screening check is not an appropriate form of assessing typical reading development.

\section{The phonics screening check}

The phonics screening check was introduced to all primary schools in England in

2012. It is designed to confirm whether pupils have learnt phonic decoding to an appropriate standard. The purpose of the check is to identify pupils who need extra help to improve their decoding skills. It is conducted individually with pupils. The check consists of 20 real words and 20 pseudo-words (non-words) that a pupil reads aloud to the teacher.

\section{The Simple View of Reading}

The Simple View of Reading (SVR) was developed by Gough and Tunmer nearly thirty years ago (Gough and Tunmer, 1986). The model proposes that reading ability or reading comprehension $(R)$ is the product of two components; decoding (D) and language comprehension $(C)$. This is often represented by the formula $R=D \times C$. The model suggests that the two components are independent of each other and that each is necessary for successful reading (Gustafson et al, 2013). Thus, neither decoding nor language comprehension is sufficient in itself to produce skilled and effective reading.

The SVR as a model of reading development has strong academic support (Aaron, 1997; Catts, Hogan and Fey, 2003; Kirby and Savage, 2008; Roberts and Scott, 2006) as well as support from policy makers in England. It was held up as a more effective model than the searchlights model which had been adopted by the National Literacy Strategy (DFEE, 1998) as a framework for supporting reading development 
in the late 1990s. This model promoted the use of multiple cues for reading unknown text. These included phonic, grammatical, graphic and contextual cues for tackling unfamiliar print. However, although the searchlights model emphasised the complex nature of reading, the model conflates the skills of word recognition and text comprehension by emphasising the use of text comprehension strategies for word recognition (Stuart, Stainthorp and Snowling, 2008) rather than keeping the skills distinct. In contrast to the searchlights model, the SVR emphasises the distinct role that word recognition and language comprehension make to reading development. Neither component is sufficient in isolation because each component makes a distinct contribution to reading ability (Gustafson et al, 2013). The combination of the two variables is a more effective predictor of reading ability than the contribution that each variable makes in isolation of the other (Gough and Tunmer, 1986; Joshi and Aaron, 2000). In 2006 Jim Rose recommended that 'the searchlights model should be reconstructed to take full account of word recognition and language comprehension as distinct processes related one to the other' (p.70).

The emphasis on linguistic comprehension in reading development which is both underpinned by research evidence and is captured in the SVR raises questions about the suitability of the phonics screening check given that it is only a test of decoding skills. Several studies have demonstrated that different skills and abilities contribute to the development of comprehension and decoding, thus supporting their dissociation in reading development (Cutting and Scarborough, 2006; Kendeou et al, 2005; 2007; Muter, Hulme, Snowling and Stevenson, 2004). However, the assumption that decoding and language comprehension make independent contributions to reading development has been challenged more recently by Tunmer and Chapman (2012) who argued that one component of oral language 
comprehension (vocabulary) affects decoding, thus demonstrating that the skills work together. This strengthens the argument for assessing both word recognition and linguistic comprehension rather than only assessing the skill of decoding.

However, the extent to which decoding and comprehension predict reading ability is dependent upon the level of reading skills. For children who are struggling readers decoding is a better predictor of reading ability but comprehension is a better predictor to explain variance in reading ability among skilled readers (Hoover and Gough, 1990). Thus, for struggling readers the phonics screening check may be useful as a predictor of their development in the skill of word recognition (decoding). However, for children who are already fluent readers, the check is not appropriate because they have already mastered the skill of word recognition. For these readers, we need to know more about their skills in comprehension skills in order to support their subsequent reading development.

Crucially, the SVR has direct practical implications for teachers (Kendeou et al, 2009). It enables teachers to assess which skill(s) may be responsible for reading difficulties and then to determine what type of intervention is necessary to remediate the difficulty (Savage, 2006). This is because the model clearly distinguishes between the skills of word recognition and language comprehension and therefore different approaches to teaching are required to develop each of these skills. Thus, if teachers know the cause of the reading failure, they are able to intervene more effectively.

Studies demonstrate that children can perform differently on decoding and comprehension. A poor reader with good comprehension but poor decoding skills (as evidenced in studies by Adlof, Catts and Little (2006) and Spooner, Baddeley and 
[Type here]

Gathercole, (2004)) may benefit from a structured multi-sensory phonic intervention designed to develop automatic grapheme-phoneme correspondence and blending skills.

A child with secure decoding but poor comprehension as evidenced in several studies (Cain, Oakhill and Lemmon, 2005; Nation, 2005; Stothard and Hulme, 1992) may benefit from a structured language intervention programme and increased exposure to oral language through a language development programme, exposure to a communication rich environment, including opportunities for play, collaboration, speaking and listening.

Finally, a child who displays poor word recognition and poor comprehension will benefit from structured intervention in both domains.

Thus, the SVR supports both assessment and targeted intervention by separating the two fundamental components of reading. Assessing children's skills in both word recognition and linguistic comprehension is more effective because teachers are then able to determine the most appropriate form of intervention. The phonics screening check, with its focus on decoding, does not inform intervention approaches for those readers who may already have secure skills in decoding and hence word recognition but require intervention in linguistic comprehension. Thus, if the skill of decoding is already secure, assessing children's linguistic comprehension skills would be a better predictor of reading skills and it would more usually help to determine what type of intervention is required to facilitate subsequent reading development.

Although the SVR is simple in the sense that it identifies only two components of reading (word recognition and language comprehension), the skills of decoding and 
comprehension are actually quite complex (Kirby and Savage, 2008; Tunmer and Greaney, 2010). The model thus risks over-simplifying the component skills of reading development.

The skill of decoding refers to the ability to quickly and with increasing automaticity 'derive a representation of the written, visual stimuli that gives access to adequate retrieval of information from the mental lexicon' (Gustafson et al, 2013: 293). Thus, the skill of decoding requires the retrieval of semantic information on the word level (Hoover and Gough, 1990). In dual-route models of word decoding access to word meaning can be gained by phonological decoding (sounding out words) or visualorthographic processing (drawing on the visual memory) (Ellis and Young, 1988). As word recognition develops there is a gradual shift from phonological decoding to orthographic processing (for example, retrieving whole-word shapes from their store in the visual memory) (Gustafson et al, 2013) and skilled readers tend to use orthographic strategies rather than the phonological strategy which relies on grapheme-phoneme conversion (Ehri and Wilce, 1987). Additionally, Kirby and Savage (2008) argue that fluency as well as accuracy is important in decoding so this skill also needs to be developed.

The danger of the SVR is that the model emphasises decoding as a key reading skill but fails to emphasise the importance of developing the sub-components of decoding which are essential in the development of decoding. Likewise, the skill of comprehension is complex and can be sub-divided into sub-skills (Kirby and Savage, 2008). Comprehension involves several linguistic domains at the same time (Gustafson et al, 2013) including phonology, semantics, grammar and pragmatics. The SVR fails to recognise the development of linguistic comprehension within each of these domains. It is therefore unsurprising that some researchers have suggested 
more complex theories which sub-divide decoding and language comprehension into sub-components (for example, Velluntino et al, 2007).

The SVR is a more effective model for assessing reading development than the phonics screening check in that it isolates the component skills of reading and assesses them separately in order to determine what type of intervention is required. Whilst the phonics screening check provides a suitable assessment of decoding and therefore may be helpful in identifying whether children have mastered the skill of decoding, it is not useful for assessing children whose reading development has advanced beyond this stage. The SVR may be more useful as a model upon which to base an assessment because it captures both component skills of reading development. Linguistic comprehension becomes more important once the skill of word recognition is established and thus the model can be used to assess children operating at different stages of reading development.

However, despite its strengths the SVR does not identify the sub-skills which contribute to word recognition or linguistic comprehension. As an assessment tool it therefore does not support teachers in understanding the component skills that children need to develop in order to become proficient in both areas. Ehri's model of reading development more usefully supports teachers in understanding the component skills that need to be developed to secure the skill of word recognition.

\section{Ehri's Model of Reading Development}

Recent theories of reading development in alphabetic orthographies suggest that a critical stage of development in learning to read is the mastery of the skill of decoding (Stuart, Stainthorp and Snowling, 2008). This skill requires beginning readers to understand the relationship between graphemes and phonemes. Ehri's 
theory of reading development (Ehri, 1992; 1995) proposes four phases in the development of automatic word reading. These phases are termed: pre-alphabetic; partial alphabetic; full alphabetic and consolidated alphabetic.

In the pre-alphabetic phase children have not yet understood the relationship between phonemes and graphemes. At this phase their reading is dependent upon visual memory (Stuart, Stainthorp and Snowling, 2008). They may be able to read environmental print, especially if it appears with salient visual cues such as logos which use specific colours and fonts (Johnston and Watson, 2007). However, if the visual cues are removed children are generally unable to recognise the word (Johnston et al, 1996). Although there is some evidence to suggest that children use visual cues in words to aid word recognition (Ehri, 1992; 1995; Frith, 1985; Gough, 1993; Seymour and Elder, 1986) some researchers have suggested that the prealphabetic phase is not an essential phase in learning to read words (Stuart and Coltheart, 1988; Jackson and Coltheart, 2001).

In the partial alphabetic phase beginning readers are able to identify the initial and final phonemes in spoken words and they are able to make some connections between graphemes and their corresponding phonemes (Stuart, Stainthorp and Snowling, 2008). Their attempts at decoding are not always accurate at this phase but they are no longer arbitrary (Stuart, Stainthorp and Snowling, 2008). They are unable to decode print systematically throughout a word and they may make logical errors based on interpreting the initial and final phonemes correctly (Johnston and Watson, 2007).

At the full alphabetic stage letters are mapped sequentially onto sounds (Stuart, Stainthorp and Snowling, 2008) and therefore children are able to make connections 
between letters and sounds all the way through a word (Johnston and Watson, 2007). At this phase children have mastered the simple and complex alphabetic code and they are able to read phonetically regular words with accuracy. Once they have decoded a word accurately children will start to automatically remember the word because at this phase children are establishing a sight vocabulary at the same time as developing proficiency in the skill of systematically decoding words.

In the consolidated alphabetic phase children start to decode words on the basis of larger units of sound. These include morphemes, onsets and rimes. At this phase children are successful word readers; their decoding is becoming increasingly accurate and their reading is becoming more automatic and fluent (Stuart, Stainthorp and Snowling, 2008).

The phonics screening check assesses children's skills against the full alphabetic stage rather than assessing whether beginning readers are operating at the pre, partial or full alphabetic phases. Thus, it fails to assess reading against a developmental framework of reading development. As such it ignores some of the earlier phases in reading development and this does not help teachers to determine appropriate forms of intervention for children whose decoding skills are not secure.

Ehri's model of reading development has practical relevance to teachers. It is a developmental model in that it identifies separate phases within developing the skill of word recognition. Teachers can use the phases to assess which point children have reached within their reading development and they can look to the subsequent phase to identify what skills the child needs to be developing next. Thus, the model can inform both teaching and assessment. The SVR fails to break down the skill of word recognition into distinct sub-phases and therefore is less informative to 
teachers in relation to how the skill of accurate word recognition develops. Ehri's model is also useful in terms of emphasising the important role that phonics plays in learning to read. The Rose Review (Rose, 2006) emphasised the importance of the alphabetic code as a body of knowledge that all children need to be taught and Ehri's theory of reading development underpins this approach to teaching reading.

However, Ehri's model falls somewhat short in neglecting the significant role that oral language comprehension plays in reading development. The SVR explicitly acknowledges that word recognition alone is insufficient to produce good readers. It has been argued that:

Vocabulary is one of the most consistent predictors of reading comprehension: children with good vocabularies understand texts better, and the predictive relationship between vocabulary and reading comprehension increases through the primary grades (Snow, 2002; Torgesen, et al, 1997).

(Stuart, Stainthorp and Snowling, 2008: 64)

Research suggests that although developing the skill of decoding makes the most significant contribution for children with reading difficulties (Gustafson et al, 2013), language comprehension is the most important predictor of reading comprehension for children with typical reading development (Gustafson et al, 2013; Hoover and Gough, 1990). Given this important finding, it is reasonable to suggest that although Ehri's model might more usefully support children with reading difficulties, it is unlikely to support those readers who are able to read words accurately and fluently but are, nevertheless, still struggling to comprehend text. The strength of the SVR is that it emphasises not only the importance of word recognition in reading development but also the crucial role that oral language comprehension plays in reading comprehension. 
[Type here]

\section{Discussion}

This paper has described two models of reading development. It has explored the strengths and limitations of each model and compared and contrasted the models. Both models are useful in helping teachers to understand how children learn to read. Ehri's model provides a developmental framework to support teachers' understanding of the phases children progress through when developing the skill of word recognition. However, the model neglects the significant role that language comprehension plays in the process of learning to read. The SVR separates the two fundamental skills that contribute to reading comprehension (word recognition and language comprehension). The model usefully informs teachers that different kinds of teaching are necessary to develop each skill and the model helps teachers to understand what types of interventions are necessary to support reading development. However, the model fails to break down each of these skills into smaller sub-skills or phases of development that contribute to both word recognition and language comprehension. Ironically, in its simplicity, the model fails to capture the complexity of the process of learning to read.

Given the strength of support for the role of oral language in the development of language comprehension and its subsequent role in reading comprehension it seems logical to support Rose in arguing the need for practitioners to teach phonics within the context of a broad and rich language curriculum.

Despite the contribution that these models make to our understanding of reading development the SVR fails to identify the pre-reading skills which children need to word recognition skills and Ehri's model neglects the role of linguistic comprehension in reading development. Despite the limitations both the SVR and Ehri's model of 
[Type here]

reading development provide more effective models of assessment than the phonics screening check. In the case of poor readers with under-developed skills in decoding, assessing the skill of decoding (which is what the phonics screening check does) is insufficient because skilled teachers will already be aware that these children are struggling to decode print. The phonics screening check therefore serves little purpose, apart from serving as an accountability tool to teachers and as a mechanism for labelling children. More importantly, it can have a detrimental impact on those children who 'fail' the test and are required to re-take it the following year.

Although the SVR and Ehri's model of reading development provide tools for developing assessment models which are theoretically informed and certainly more informative than the phonics screening check, they do not provide perfect models for assessing reading development. Assessing children in 'word recognition' in the SVR and against the partial and full alphabetic phase in Ehri's model may be unhelpful for the weakest readers who are not operating within either of the alphabetic phases. In the case of these children teachers need to assess other skills which can contribute to the development of the skill of decoding. These are the skills which precede decoding at the level of the phoneme and from a developmental perspective need to be secure before children can blend the smallest units of sound (phonemes). These skills include: compound word blending and segmenting; syllable blending and segmenting, onset and rime blending and segmenting, phoneme addition, phoneme deletion and phoneme substitution. Once these skills are secure children can be supported to develop the skill of blending and segmenting at the level of the phoneme. Assessing children's decoding skills at the phoneme level (i.e. as in the phonics screening check) does not inform teachers' understanding of how to support 
children who are not secure with this skill. More detailed information is required in order to help children develop this skill. Additionally, word recognition is not just an auditory process. It requires the development of skills such as visual discrimination, visual memory and visual sequential memory. The phonics screening check, the SVR and Ehri's framework all neglect these fundamental pre-reading skills which underpin reading development.

\section{Conclusion}

The phonics screening check is unhelpful in terms of informing intervention for the weakest readers and could have a detrimental impact on the progress of the mostable readers who need to develop their skills in reading comprehension. As a starting point for assessment teachers should use the SVR to assess children's skills in both word recognition and linguistic comprehension. This will broadly inform the type of intervention that is required to support a child's reading development. Children with poor word recognition skills can then subsequently be assessed against Ehri's developmental framework to identify which phase they are working within. For children who are working at the pre or partial alphabetic phases a more detailed assessment tool may be required and should include skills such as compound word blending, syllable blending, onset and rime blending, phoneme addition, phoneme deletion and phoneme substitution. As reading is also a visual process poorer readers should also be assessed against a framework for visual skills development which includes visual attention, visual discrimination, visual memory and visual sequential memory. The phonics screening check fails to capture the complexity of reading development and this paper argues that a more detailed framework for assessment, based on theoretical models of reading development, would be more appropriate. 
[Type here]

\section{References}

Aaron, P.G. (1997), 'A component-based approach to the diagnosis and treatment of reading disabilities', in B. Ericson and J. Ronnberg (Eds), Reading Disability and its Treatment (pp.37-66), EMIR, Report No. 2, Norrkoping: Eve Malmquist Institute for Reading, Linkoping University.

Adlof, S.M., Catts, H.W., and Little, T.D. (2006), 'Should the Simple View of Reading include a fluency component?' Reading and Writing, 19, pp.933-958.

Cain, K., Oakhill, J.V., and Lemmon, K., (2005), 'The relation between children's reading comprehension level and their comprehension of idioms', Journal of Experimental Child Psychology', 90, pp.65-87.

Catts, H.W., Hogan, T.P., and Fey, M.E. (2003), 'Sub-grouping poor readers on the basis of individual differences in reading-related abilities', Journal of Learning Disabilities, 36, (3), pp.151-164.

Cutting, L.E., and Scarborough, H.S. (2006), 'Prediction of Reading Comprehension: Relative Contributions of Word Recognition, Language Proficiency and other Cognitive Skills can depend on how Comprehension is measured', Scientific Studies of Reading, 10, pp.277-299.

Department for Education (DfE) (2012), Teachers' Standards in England, DFE.

Department for Education (DfE) (2010), The Importance of Teaching: The Schools White Paper 2010, DfE

Department for Education (DfE) (2016), Educational Excellence Everywhere, DFE.

DFEE, (1998), The National Literacy Strategy: Framework for Teaching, London: DFEE.

Department for Education and Skills (2007), Letters and Sounds, London: DFES.

Ehri, L.C., (1992), 'Reconceptualising the development of sight word reading and its relationship to recording', in Gough, P.B., Ehri, I.D, Treiman, R. (Eds), Reading Acquisition, Hillsdale, NJ: Erlbaum.

Ehri, L.C., (1995), 'Phases of development in learning to read words by sight', Journal of Research in Reading, 18, pp.116-125.

Ehri, L. C. (2005) Development of Sight Word Reading: Phases and Findings, in The Science of Reading: A Handbook (eds M. J. Snowling and C. Hulme), Blackwell Publishing Ltd, Oxford, UK.

Ehri, L.C., and Wilce, L.S., (1987), 'Cipher versus cue reading: an experiment in decoding acquisition', Journal of Educational Psychology, 79, pp.3-13.

Ellis, A., and Young, A., (1988), Human Cognition Neuropsychology, London: Lawrence Erlbaum.

Frith. U. (1985), 'Beneath the surface of developmental dyslexia', in K.E. Patterson, J.C. Marshall and M. Coltheart (Eds), Surface Dyslexia: Neuropsychological and cognitive Studies of Phonological Reading, London: Erlbaum (pp.301-330). 
Frith, U. (1986). A developmental framework for developmental dyslexia. Annals of Dyslexia, 36, 69-81.

Goodman, K.S. (1976) Reading: a psycholinguistic guessing game. In H. Singer and R.B. Ruddell (eds.) Theoretical Models and Processes of Reading, Newark, Delaware: International Reading Association.

Gough, P.B, (1993), 'The beginning of decoding', Reading and Writing, 5, pp.181192.

Gough, P.B. and Tunmer, W.E. (1986), 'Decoding, reading and reading disability', Remedial and Special Education, 7, (1), pp.6-10.

Gurney P.W. (1988) Self-Esteem in Children with Special Educational Needs Routledge: London and New York.

Gustafson, S., Samuelsson, C., Johansson, E., and Wallmann, J. (2013), 'How Simple is the Simple View of Reading?' Scandinavian Journal of Educational Research, 57, (3), pp.292-308.

Hoover, W.A., and Gough, P.B., (1990), 'The Simple View of Reading: Reading and Writing', An Interdisciplinary Journal, 2, pp.127-160.

Jackson, N.E., and Coltheart, M (2001), Roots to Reading: Success and Failure, New York: Psychology Press.

Johnston, R., and Watson, J., (2007), Teaching Synthetic Phonics', Exeter: Learning Matters.

Johnston, R.S., Anderson, M., and Holligan, C., (1996), 'Knowledge of the alphabet and explicit awareness of phonemes in pre-readers: the nature of the relationship', Reading and Writing, 8, pp.217-234.

Joshi, R.M., and Aaron, P.G. (2000), 'The Component Model of Reading: Simple View of Reading made a little more complex', Reading Psychology', 21, pp.85-97.

Kendeou, P., Lynch, J.S., van den Broek, P., Espin, C.A., White, M.J., and Kremer, K.E., (2005), 'Developing Successful Readers: Building early comprehension skills through television viewing and listening', Early Childhood Education Journal, 33, pp.91-98.

Kendeou, P., Savage, R., and van den Broek, P., (2009), 'Revisiting the Simple View of Reading', British Journal of Educational Psychology, 79, (2), 353-370.

Kendeou, P., van den Broek, P., White, M., and Lynch, J., (2007), 'Pre-School and Early Elementary Comprehension: Skill Development and Strategy Interventions', in D.S.McNamara (Ed), Reading Comprehension Strategies: theories, interventions and technologies, (pp. 27-45), Mahwah, NJ: Erlbaum.

Kirby, J., and Savage, R.S. (2008), 'Can the Simple View deal with the Complexities of Reading?' Literacy, 42, (2), pp.75-82.

Muter, V., Hulme, C., Snowling, M.J., and Stevenson, J., (2004), 'Phonemes, rimes, vocabulary and grammatical skills as foundations of early reading development: evidence from a longitudinal study', Developmental Psychology, 40, pp. 665-681. 
Nation, K. (2005), 'Children's reading comprehension difficulties', in M. Snowling and C. Hulme (Eds), The Science of Reading: a handbook, Oxford: Blackwell.

Roberts, J.A., and Scott, K.A., (2006), 'The Simple View of Reading: Assessment and Intervention', Topics in Language Disorders, 26, pp.127-143.

Rose, J., (2006), Independent Review of the Teaching of Early Reading: Final Report, London: DFES.

Savage, R. (2006), 'Reading comprehension is not always the product of nonsenseword decoding and linguistic comprehension: evidence from teenagers who are extremely poor readers', Scientific Studies of Reading, 10, (2), pp.143-164.

Seymour, P.H.K., and Elder, L. (1986), 'Beginning Reading without Phonology', Cognitive Neuropsychology', 1, 1-36.

Spooner, A.L.R., Baddeley, A.D., and Gathercole, S.E., (2004), 'Can reading and comprehension be separated in the Neale analysis of reading ability?' British Journal of Educational Psychology, 74, pp.187-204.

Stothard, S.E., and Hulme, C. (1992), 'Reading comprehension Difficulties in Children: the role of language comprehension and working memory skills', Reading and Writing, 4, pp.245-256.

Stuart, M., and Coltheart, M (1988), 'Does reading develop in a sequence of stages?' Cognition, 30, 139-181.

Stuart, M., Stainthorp, R., and Snowling, M. (2008), 'Literacy as a Complex Activity: deconstructing the Simple View of Reading', Literacy, 42, (2), 59-66.

Tunmer, W., and Greaney, K. (2010), 'Defining Dyslexia', Journal of Learning Disabilities, 43, pp. 229-243.

Tunmer, W.E., and Chapman, J.W., (2012), 'The Simple View of Reading Redux: vocabulary knowledge and the independent components hypothesis', Journal of Learning Disabilities, 45, (5), pp.453-466.

UKLA (2012), Phonics Screening Check fails a generation of able readers, https://ukla.org/news/story/phonics screening check fails a generation of able re aders [accessed 24.6.16] 